\title{
A Morphological Study on the Carbon Particles from Wood Fiber Waste via Hydrothermal Carbonization Process
}

\author{
Saidatul S. Jamari, Jonathan R. Howse, and Azlinna A. Bakar
}

\begin{abstract}
Wood fiber waste is abundantly produced from the medium density wood fiber industry. The production of carbon from biomass is having more intention from the researcher due to the application. In this research, the conversion of biomass from wood fiber waste into carbon particle via hydrothermal carbonization (HTC) process is chosen. In this experiment, wood fiber and water were added in a pressure vessel and heated up to temperature between $200-220^{\circ} \mathrm{C}$ for 4 hours. Analyses were carried out using Elemental Analyzer, TGA, FTIR and FESEM for the characterization phase. The carbon value recorded an improvement as the $\mathrm{O} / \mathrm{C}$ ratio of raw material is higher than the HTC products. The surface morphology obtained from FESEM showed pores on the surface of the HTC product suggesting a processing route to complicated carbon based structures. It can be concluded that both processes is practicable method to convert biomass into value added product.
\end{abstract}

Index Terms-Carbon, hydrothermal, morphology, wood wastes.

\section{INTRODUCTION}

Biomass is a renewable, potentially sustainable and environmentally benign source of energy. Biomass contribute approximately $12 \mathrm{wt} \%$ of today's world primary energy supply, while in many developing countries estimately 40 $\mathrm{wt} \%$ to $50 \mathrm{wt} \%$ [1]. World production of biomass is estimated at 146 billion metric tons a year [2]. There are abundant volumes of wood fiber waste production which normally being dumped to the landfill. The total land area in Malaysia is 32.98 million hectar. According to the Malaysian Timber Council (MTC) in 2009, the total production of logs based on the total land area is 18.27 million $\mathrm{cm}^{3}$ has produced 0.44 million $\mathrm{m}^{3}$ of $\operatorname{logs}, 0.27$ million $\mathrm{m}^{3}$ of sawn timber and 683 million $\mathrm{m}^{3}$ of plywood in 2009 [3]. Traditionally, biomass has been utilized through direct combustion. Burning biomass produces some pollutants, including dust and the acid rain gases sulphur dioxide $\left(\mathrm{SO}_{2}\right)$ and nitrogen oxides $\left(\mathrm{NO}_{\mathrm{x}}\right)$. The abundant production of wood fiber waste is an attractive option to create new technologies to convert biomass waste especially wood fiber waste into value added product.

Manuscript received February 9, 2013; revised May 5, 2013

Saidatul S. Jamari is with the Faculty of Chemical and Natural Resources Engineering, Universiti Malaysia Pahang, 26300, Gambang, Pahang, Malaysia (e-mail: sshima@ump.edu.my)

Jonathan R. Howse is with the Department of Chemical and Biological Engineering, University of Sheffield, S1 3JD, Sheffield, United Kingdom (e-mail: j.r.howse@sheffield.ac.uk)
There are several methods to convert this biomass waste product into value added product, such as coalification, pyrolysis, gasification and hydrothermal gasification processes. The hydrothermal carbonisation (HTC) process has the ability in maintaining the carbon elements from the biomass polymeric structure to solid form. HTC generate both solid carbonaceous material and water soluble organic liquid. The solid carbonaceous material, also known as biochar, is defined as fine grained charcoal, high in organic carbon and largely resistance to decomposition. HTC process can release one third of the combustion energy throughout dehydration [4]. Its' carbon efficiency is close to 1 after an adequate reaction time under proper condition. The conversion of biomass into carbon particle has potential application in many fields, such as water purification, carbon fixation, energy storage, fuel cell catalysis, carbon dioxide sequestration, bioimaging, drug delivery, and gas sensors [5].

Biomass and its utilization have been intimately associated to renewable energy in the recent years [6], [7]. However, the undesirable properties of biomass such as high moisture content and its heterogeneous nature pose a barrier to its competitiveness in the energy generation market.

The need for efficient biomass conversion technologies and high cost of conventional carbon nanoparticle synthesis production, such as arc discharge and steam explosion, is a factor for commercialization. The hydrothermal carbonization method represents one of the promising chemical routes to treat this biomass because of the intrinsic advantages such as benign environment, versatile chemistry, enhanced reaction rate and economic cost.

In this paper, the conversion of surface structure of the carbon particles from wood fiber wastes is presented. The quality of products under different operating conditions will also be illustrated. The results presented in this paper will also offer inspiration on the future work for the development of the HTC process.

\section{MATERIALS AND METHOD}

\section{A. Materials}

The wood fiber is a by-product of the medium density fiberboard (MDF) taken from a fiberboard manufacturing company. Acetic acid powder from Sigma Aldrich was used as the catalyst.

\section{B. Method}

A supercritical unit (2 liters) was used as the reactor. $175 \mathrm{~g}$ of wood fiber waste were used and immersed with water (1 
liter) inside the reactor. Acetic acid was added as a catalyst. The reaction takes place at $180-220^{\circ} \mathrm{C}$ for 4 hours. Then, the product subjected to drying in an oven at $105^{\circ} \mathrm{C}$ for 2 hours.

\section{Particles Characterization}

Carbon particles analyses are important to determine the characteristics and structural properties of the product. The properties of carbon produced were analyzed based on the morphological characteristics which are the diameter size of particles and the surface area of the particle. This can be done through Field Emission Scanning Electron Microscopy (FESEM). The percentage value of carbon products was determined from the Perkin Elmer Elemental Analyzer. While, the FTIR analysis identify the component and chemical compositions which exist on the surface of wood fiber waste after the HTC process.

\section{RESULT AND DISCUSSION}

\section{A. CHNO Analysis}

The chemical characteristic of the wood fibers carbon particles were determined from their elemental contents, such as carbon $(\mathrm{C})$, hydrogen $(\mathrm{H})$, oxygen $(\mathrm{O})$. These elements are found in the lignocellulose material; therefore, a measurement of these elements is able to show the effect of the HTC process on our samples. This method has been applied widely in the carbonaceous material characterization procedure where an elemental analyzer is used [8].

In general, hydrothermal treatment decomposes the raw materials and produced purer carbon products. The molecular formula of the studied samples, based on one $\mathrm{C}$ atom, can be written as $\mathrm{CHxOy}$, shows constant reduction of hydrogen and oxygen atoms fraction in the wood fibers carbon particles compared to the raw samples [9]. In the molecular formula, the number of atom constitute for every element in the substance can be seen, for example in the raw wood fibers, two atoms of hydrogen and one atom of oxygen is bonded with its one atom of carbon. As shown in Table I, the molecular formula for biocarbons, which contain higher carbon content, will have fewer atoms linked with the carbon atom.

TABLE I: CHO VALUES OF THE EFB AND WC BIOCARBONS HEATED FOR 22 HOURS

\begin{tabular}{cccccc}
\hline $\begin{array}{c}\text { Temperature } \\
\left({ }^{\circ} \mathrm{C}\right)\end{array}$ & $\begin{array}{c}\mathrm{C} \\
(\mathrm{wt} \%)\end{array}$ & $\begin{array}{c}\mathrm{H} \\
(\mathrm{wt} \%)\end{array}$ & $\begin{array}{c}\mathrm{N} \\
(\mathrm{wt} \%)\end{array}$ & $\begin{array}{c}* \mathrm{O} \\
(\mathrm{wt} \%)\end{array}$ & $\begin{array}{c}\text { Molecular } \\
\text { formula, } \\
\mathrm{CH}_{\mathrm{x}} \mathrm{O}_{\mathrm{y}}\end{array}$ \\
\hline 0 (Raw) & 47.03 & 6.51 & 0 & 46.46 & $\mathrm{CH}_{1.66} \mathrm{O}_{0.74}$ \\
180 & 52.76 & 5.91 & 0 & 41.33 & $\mathrm{CH}_{1.34} \mathrm{O}_{0.59}$ \\
200 & 64.15 & 4.58 & 0 & 31.27 & $\mathrm{CH}_{0.86} \mathrm{O}_{0.37}$ \\
220 & 67.91 & 4.85 & 0 & 27.24 & $\mathrm{CH}_{0.86} \mathrm{O}_{0.30}$ \\
\hline
\end{tabular}

$* \mathrm{O}(\mathrm{wT} \%)=100-\mathrm{C}(\mathrm{WT} \%)-\mathrm{H}(\mathrm{WT} \%)-\mathrm{N}(\mathrm{WT} \%)$

The value for the wood carbon particles after being operated for 22 hours gives a clearer view on the transformation of trends. The carbon content increased significantly when the temperature was raised while the value of oxygen decreased. In addition, the value of hydrogen showed a slight decrement as this atom has small molecular weight compared to carbon and oxygen. As the result, it can be assumed that active removal of oxygen and hydrogen elements occurred in the HTC process.

\section{B. Morphological Analysis}

The morphology of wood fiber wastes was investigated to study the structure before and after processing. In the lignocellulose structure, the inner layer, a well-organized cellulose polymer with the attachment of the hemicelluloses structure can be found. In the amorphous region, hemicellulose polymer can be found, which has higher tendency to breakage during the pretreatment process, compared to the crystalline region. The decomposition temperature of lignin starts at $200^{\circ} \mathrm{C}$ [10] at a slow rate. Therefore, the surface structure of the wood fiber wastes shows a slight difference before and after the HTC process. However, it is important to realize the degree to which the initial morphology and structure is retained regardless of the complicated chemistry and rearrangement taking place at the molecular level.

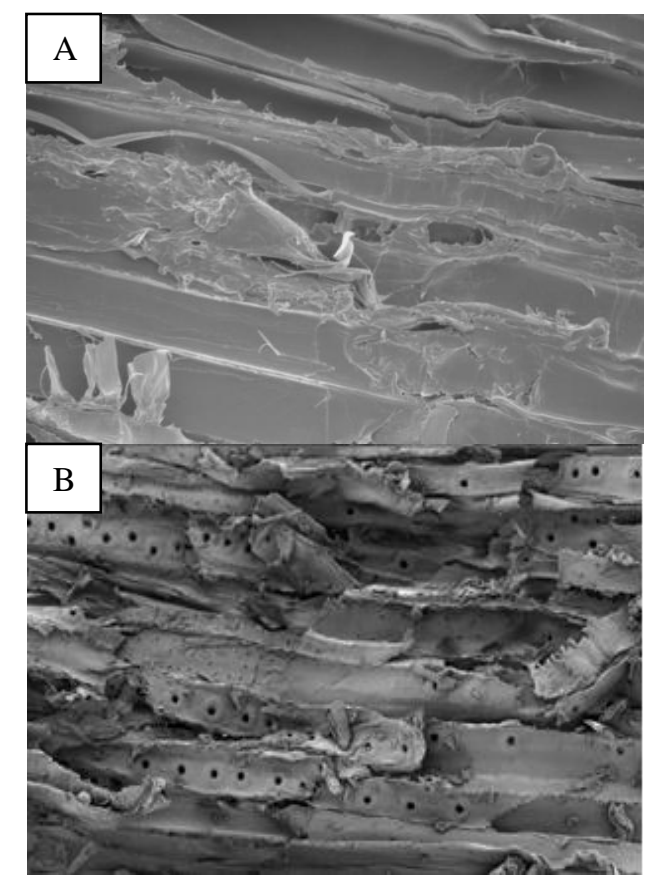

Fig. 1. Morphology of A: Raw wood fiber, B: Wood fiber carbon particles at $200^{\circ} \mathrm{C}$ (Magnification: $\left.100 \mu \mathrm{m}\right)$

The damages on the outer layer of the wood fibers can be seen on the carbon particles compared to the untreated wood fibers as illustrated in Fig. 1. Small holes can be seen on the morphology of the products as a repetition of the pores occurs at similar distance with another pore. This can be assumed that a rupture process of fibers on the weakest spot, which is amorphous part, of the fiber polymeric bonds starts to occur at temperature $200^{\circ} \mathrm{C}$ [11].

Based on the Fig.2, the formation of globular structure on the product surface area can be seen. It can also be concluded that the disarrangement of our product occurred on the surface structure and the inner fiber structure was not severely affected, although higher percentage of carbon content was 
recorded from the product. The unchanging physical structure might occur due to the stable and complex carbon scaffolds, which require higher temperature to be decomposed.

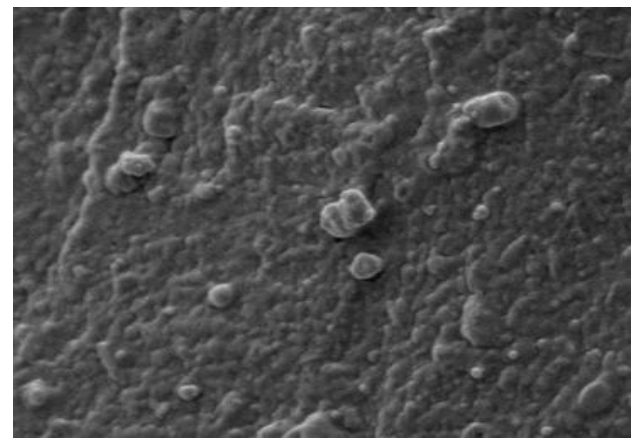

Fig. 2. Surface morphology of carbon products at magnification, $100 \mathrm{~nm}$.

\section{FTIR Analysis}

Fig. 3 shows the FTIR spectra of unmodified raw of wood fiber waste and chemically modified at two different process conditions. Clear differences can be detected in the infrared spectra, both in the different absorbance values and shapes of the bands and in their location. A decrease in the intensity of the $\mathrm{O}-\mathrm{H}$ absorption band was observed in Fig. 3 indicating that the hydroxyl group contents in the product reduced after reaction. The spectrum peaks at range 3 , increased compared to raw which is for $\mathrm{C}=\mathrm{O}$ stretching. There are no significant differences between spectra for unmodified and chemically modified lignin samples. These are caused probably by the interactions between the functional groups. Generally, wood fiber waste contains hemicellulose and lignin. Therefore, stronger presence of single bonds components, such as $\mathrm{O}-\mathrm{H}$, $\mathrm{C}-\mathrm{H}$ and $\mathrm{C}-\mathrm{O}$ bonds, are expected on the surface of wood fiber wastes. Small peaks of $\mathrm{C}=\mathrm{O}$ and $\mathrm{C}=\mathrm{C}$ bonds were also detected in these spectra proving the existence of hemicellulose and lignin on the raw materials surface structure.



Fig. 3. FTIR spectra of untreated and treated WFW at different process condition

\section{Charing Qualitative Analyisis}

The colour transformation behaviour for the wood fibers materials, before and after the HTC process, were investigated by using the Red-Blue-Green (RGB) colour model. The RGB model is an additive of three basic colours, which are red, green and blue, to produce the other colour. The ratios of the RGB value provide the statistical data for the biocarbons' colour characteristics. The RGB value for white is $255: 255: 255$, while black is $0: 0: 0$, which is similar to the coal (Type I) value. Therefore, it is important to determine the statistical value of our products to verify the similarities with coal in terms of colour analysis.

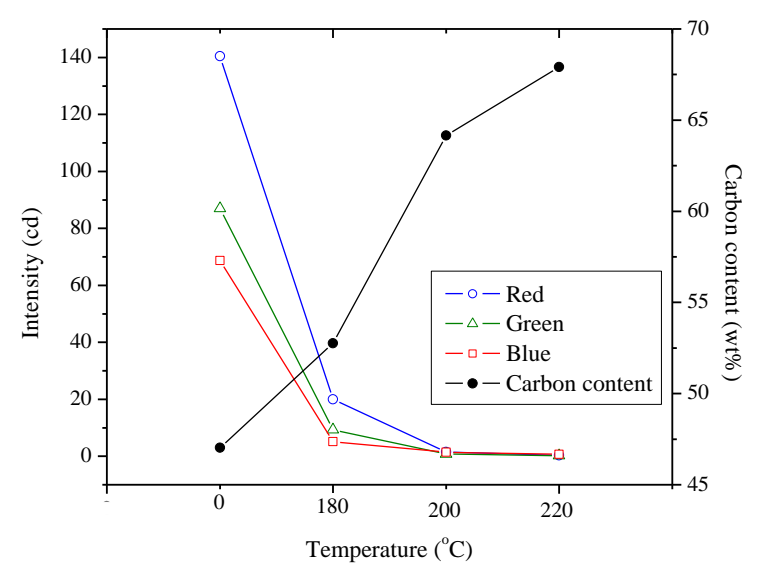

Fig. 4. The correlation of the RGB values of wood fibers carbon products heated for 22 hours with the carbon content.

The relationships of the RGB values for EFB and WC biocarbons processed at different temperatures, $0,180,200$ and $220^{\circ} \mathrm{C}$, for 22 hours with the percentage of carbon content are investigated. Fig. 4 illustrated that the RGB intensity for each material is approaching zero, purer carbon product is obtained. Therefore, this simple analytical study on the colour transformation of the biocarbons is able to provide information on the products quality.

\section{CONCLUSION}

Through this study, the following summary and conclusions were obtained due to the several achievements from conversion of wood fiber waste into carbon particle via hydrothermal carbonization process:

1) Both process increase the amount of carbon content in the final products, automatically improves its quality as an energy source.

2) FTIR study revealed that from the spectrum shows the main oxygen groups present in the raw are carbonyl, ethers and alcohols group which are normally present in plant cellulose.

The sample can be varies at other operating temperature and at different time taken for reaction to take place. Further study on the surface area of the product need to be done, e.g. Brauneur Emmet Teller (BET) analysis.

\section{ACKNOWLEDGMENT}

The authors express their thanks to Universiti Malaysia Pahang and Malaysian Government for funding. Many thanks are also given to the technicians involved in helping us to carry out the analyses.

\section{REFERENCES}

[1] K. Bossong. (2012). Renewable Energy Provided 11\% of Domestic Energy Production in 2010. [Online]. Available: http://www.renewableenergy.com.

[2] M. Balat and G. Ayar, "Biomass Energy in the World, Use of Biomass and Potential Trends," Energy Sources, vol. 27, pp. 931-940, 2005.

[3] T. Brandt and J. Yong, Market Watch 2011 - The Timber Sector in Malaysia, Malaysia-German Chamber of Commerce \& Industry, 2010 
[4] A. Funke and F. Ziegler, "Hydrothermal carbonization of biomass: A summary and discussion of chemical mechanisms for process engineering," Biofuels, Bioprod. Bioref, vol. 4, pp. 160-177, 2010.

[5] B. Hu, K. Wang, L. Wu, S. H. Yu, M. Antonietti, and M. Titirici, "Engineering Carbon Materials from the Hydrothermal Carbonization Process of Biomass," Adv. Mater, vol. 22, pp. 813-828, 2010.

[6] J. Chew and V. Doshi, "Recent advances in biomass pretreatment Torrefaction fundamentals and technology," Renewable and Sustainable Energy Reviews, vol. 15, pp. 4212-4222, 2011.

[7] S. Kaewluan and S. Pipatmanomai, "Potential of Synthesis Gas Production from Rubber Wood Chip Gasification in a Bubbling Fluidised Bed Gasifier," Energy Conversion and Management, vol. 52, pp. 75-84, 2011.

[8] J. S. Tumuluru, S. Sokhansanj, C. T. Wright, J. R. Hess, and R. D. Boardman, "A Review on Biomass Torrefaction Process and Product Properties," Symposium on Thermochemical Conversion, 2011.

[9] A. Demirbas, "Combustion Characteristics of Different Biomass Fuels," Progress in Energy and Combustion Science, vol. 30, pp. 219-230, 2004

[10] H. Yang, R. Yan, T. Chin, D. T. Liang, H. Chen, \& C. Zheng, " Thermogravimetric Analysis-Fourier Transform Infrared Analysis of Palm Oil Waste Pyrolysis,” Energy \& Fuels, vol. 18, pp. 1814-1821, 2004.

[11] S. S. Jamari and J. R. Howse, "The effect of the hydrothermal carbonization process on palm oil empty fruit bunch," Biomass and Bioenergy, vol. 47, pp. 82-90, 2012.

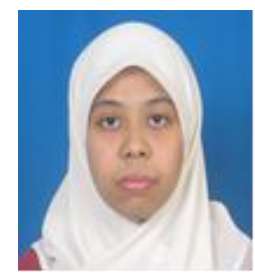

Pahang, Malaysia.
Saidatul S. Jamari was born in Malacca on 28 November 1984. She received her degree in Bachelor of Chemical Engineering, Universiti Putra Malaysia, Malaysia. Then, from 2008 to 2011, further her study to the $\mathrm{PhD}$ level in the Department of Chemical Engineering, University of Sheffield, United Kingdom. Currently, she is working as a lecturer in the Faculty of Chemical and Natural Resources Engineering, Universiti Malaysia 